\title{
Coronary artery bypass surgery in Syrian refugees
}

\author{
Outcomes in a Turkish tertiary center
}

Mazlum Şahin, MD, Semi Ozturk, MD, Tuğba İ. Mert, MD, Gündïz Durmus,, MD, Mehmet Mustafa Can, MD.

\section{ABSTRACT}

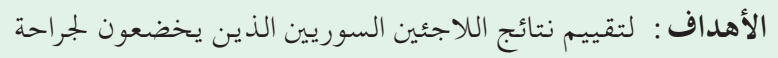

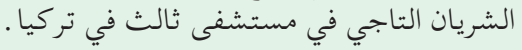

$$
\begin{aligned}
& \text { الطريقة : بحثنا بالوفيات في المستشفى وجميع مسببات الوفيات الوفاة لعام }
\end{aligned}
$$

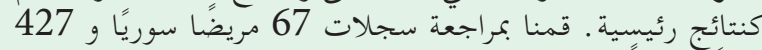

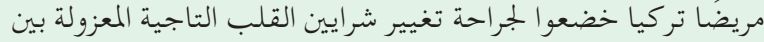

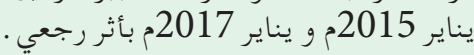

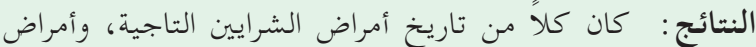

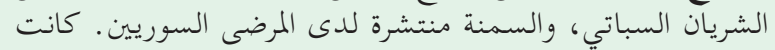

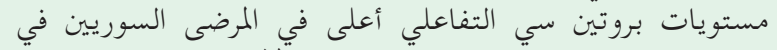

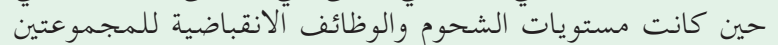

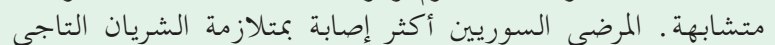

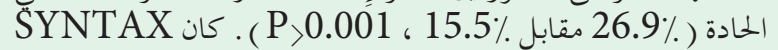

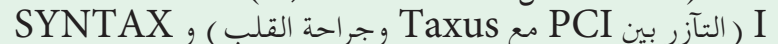

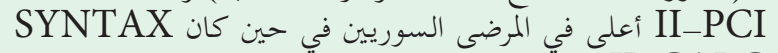

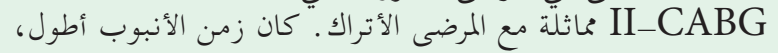

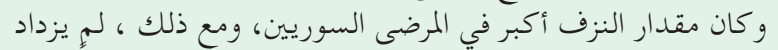

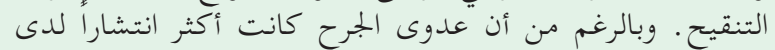

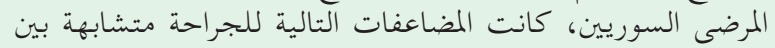

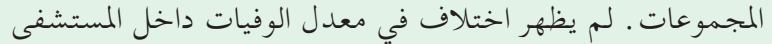

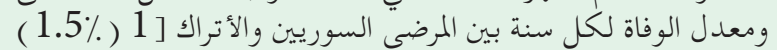

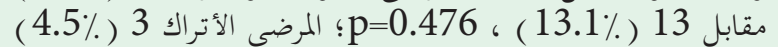

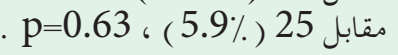

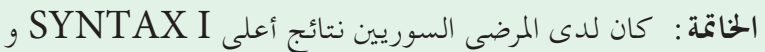
SYNTAX II CABG بينما نتيجة SYNTAX II PCI

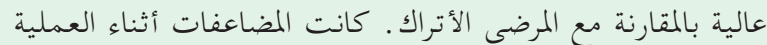

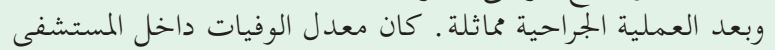

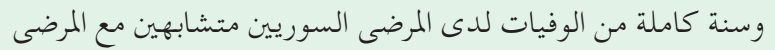

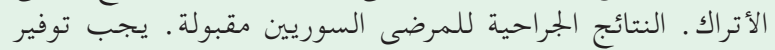

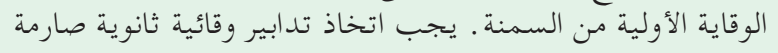

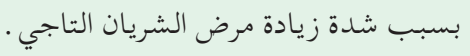

Objectives: To assess outcomes of Syrian refugees undergoing coronary artery bypass surgery in a tertiary hospital in Turkey.
Methods: We sought for in-hospital mortality and one year all-cause mortality as the main outcomes. We reviewed records of 67 Syrian and 427 Turkish patients undergoing isolated coronary bypass surgery between 2015 January and 2017 January retrospectively.

Results: History of coronary, peripheral and carotid artery diseases and obesity were more frequent in Syrian patients. C-reactive protein levels were higher in Syrian patients whereas lipid profiles and systolic functions of the 2 groups were similar. Syrian patients more frequently presented with the acute coronary syndrome $(26.9 \%$ versus $15.5 \%, p<0.001$ ). SYNTAX I (Synergy between PCI with Taxus and Cardiac Surgery) and SYNTAX IIPCI were higher in Syrian patients whereas SYNTAX II-CABG was similar with Turkish patients. Extubation time was longer and amount of the hemorrhage was greater in Syrian patients; however, bleeding revision was not increased. Although wound infection was more frequent in Syrian patients, postoperative complications were similar between groups. In-hospital mortality and one year all-cause mortality did not differ between Syrian $(n=1 ; 1.5 \%$ versus $n=13 ; 13.1 \%)(p=0.476)$ and Turkish patients $(n=3 ; 4.5 \%$ versus $n=25 ; 5.9 \%)(p=0.63)$.

Conclusion: Syrian patients had higher SYNTAX I and SYNTAX II PCI scores, but not SYNTAX II CABG score compared with Turkish patients. Intraoperative and postoperative complications were similar. In-hospital mortality and one year all-cause mortality of Syrian patients were similar with Turkish patients. Surgical outcomes of Syrian patients were acceptable. Primary prevention of obesity must be provided. Aggressive secondary preventive measures must be taken due to increased severity of coronary artery disease.

Saudi Med J 2018; Vol. 39 (8): 781-786 doi:10.15537/smj.2018.8.22498

From the Department of Cardiology, Haseki Training and Research Hospital, Millet Cadddesi Aksaray, Fatih, Istanbul, Turkey.

Received 24th August 2018. Accepted 19th July 2018.

Address correspondence andreprint request to: Dr. Semi Ozturk, Department of Cardiology, Haseki Training and Research Hospital, Millet Cadddesi Aksaray, Fatih, Istanbul, Turkey.E-mail: semi_ozturk@yahoo.com ORCID ID: orcid.org/0000-0001-5696-6849 
C onflict in Syria since 2011 caused a massive refugee displacement. More than 5 million refugees live outside Syria. ${ }^{1}$ This is the biggest immigration after World War. ${ }^{2}$ Turkey has accepted the vast majority of refugees. By the date of 22 February 2018, formally reported number of Syrian refugees (SR) under temporary protection of Turkey is 3.554.072. ${ }^{2}$ Istanbul hosts more than half million SR. The success of Turkey in providing healthcare to a large population of refugees was confirmed and reported by international delegations. ${ }^{3}$ A significant number of papers were published reporting about the health status of SR in Turkey, Jordan, and Palestine. ${ }^{4-6}$ Trauma-related surgical problems, acute infectious disease and psychiatric disorders are the most common presentations of SR. ${ }^{7}$ Beyond aforementioned diseases related with war and migration, cardiovascular disease was the leading cause of death in Syria before the civil war. ${ }^{8}$ Only a few papers focused on cardiovascular disease in SR, which deserves more attention. ${ }^{9,10}$ Single paper exists which evaluated outcomes of SR undergoing coronary bypass surgery. ${ }^{11}$ Given the value of this early report, it only presents Syrian patients' records and it lacks comparison with Turkish patients. Furthermore, the study was performed in a Turkey's border city, where SR mostly stayed in camps. Therefore, it was not possible to obtain follow up outcomes. Since Istanbul is a final destination where most SR settle down; thus, we were able to estimate mortality rates in our study.

It is evident that SR tend to be under diagnosed and under treated during years of war. We investigated outcomes of SR undergoing coronary artery bypass (CABG) surgery and compared outcomes with Turkish patients. We sought whether SR have different complication and mortality rates.

Methods. In this retrospective cohort, we sought for in-hospital mortality and one year all-cause mortality as main outcomes. Additionally, preoperative risk factors, operative and postoperative complications were also evaluated. We reviewed records of 511 patients between 2015 January and 2017 January undergoing isolated coronary bypass surgery in Haseki Training and Research Hospital, a tertiary center in Istanbul. We excluded 12 urgent surgeries and 16 cases who had a diagnosis of malignancy. Patients who underwent

Disclosure. Authors have no conflict of interests, and the work was not supported or funded by any drug company. off-pump surgery were included in the study $(\mathrm{n}=28)$. Eventually, 426 Turkish and 67 Syrian patients were included in the study.

Routine preoperative examinations were performed in all patients. Electrocardiography, echocardiography, carotid Doppler ultrasound and respiratory function tests were performed. Carotid artery angiography was performed in case Doppler ultrasound revealed stenosis above $50 \%$. Twenty-four patients who had carotid artery stenosis underwent carotid endarterectomy (CEA), according to European Society for Vascular Surgery guidelines, at the time of CABG.

The median sternotomy was performed in all cases. Left internal thoracic artery (LITA) and saphenous venous grafts were harvested. Left internal thoracic artery was used for left anterior descending artery where possible. Cardiopulmonary bypass (CPB) was performed via right atrial and aortic cannulation, the aorta was cross-clamped after cooling to $28-32^{\circ} \mathrm{C}$. During $\mathrm{CPB}$, mean arterial pressure was maintained at $50-70 \mathrm{~mm} \mathrm{Hg}$. Myocardial protection was achieved with continuous retrograde blood cardioplegia whereas anterograde blood cardioplegia was performed at 20-minute intervals. During coronary bypass grafting, proximal anastomoses were performed under side clamp. Anterograde cardioplegia was delivered in the cases only with short estimated operation period. Proximal anastomoses were made under cross clamping in patients with aortic calcifications. Temporary pacemaker was placed in patients suffering from arrhythmia. Coronary bypass was terminated after warming. Sternum was closed when hemostasis was achieved.

Patients were routinely followed up by cardiovascular surgeon and cardiologist on the first week and fourth week of discharge. After the first-month, cardiologist examined the patients at 3-month intervals. Mortality data mostly depends on regular examinations recorded in hospital software data. Additionally, searches were conducted from national death reporting system (https://obs.gov.tr). Phone calls with patients or relatives were performed when needed. The study was approved by the local ethical committee.

Statistical analysis. Statistical Analysis for Social Sciences for Windows, Version 17.0. (Chicago: SPSS Inc.) was used for statistical analysis. The normality of the data was tested with Kolmogorov-Smirnov test. Mean \pm standard deviation (SD), median and interquartile range (IQR) were used for normally and non-normally distributed variables. Percentages were used for categorical data. Differences in categorical variables between groups were assessed with Chi-square test. Mann-Whitney U or Student's T-test were used to 
assess differences between patient subgroups. P-value $<0.05$ was considered statistically significant. Survival was examined by Kaplan-Meier analysis between groups. The log-rank test was used to compare survival estimates.

Results. Baseline characteristics. In this retrospective cohort, we sought for in-hospital mortality and one year all-cause mortality as main outcomes. Additionally, preoperative risk factors, operative, and postoperative complications were also evaluated. The study included 426 Turkish and 67 Syrian patients were included in the study. Baseline characteristics of groups are presented in Table 1. Turkish patients were older. Both groups of patients were overweighted; however, BMI is significantly higher in Syrian patients $(29.9 \pm 3.6$ versus $27.1 \pm 3.8 ; \quad p<0.001)$. Obesity (BMI $\geq 30$ ) was more frequent in Syrian (43.3\% versus 20.7\%, $p<0.001$ ). Smoking and hypertension were more frequent in Turkish patients. The previous history of coronary artery disease was more frequent in Syrian patients. Although peripheral and carotid artery disease were more frequent in Syrian patients, the severity of carotid artery stenosis did not differ. Both patient groups have similar lipid profiles; however, Syrian patients have significantly higher CRP. Syrian patients were more frequently presented with the acute coronary syndrome (26.9\% versus $15.5 \%, p<0.001)$. Systolic functions of the 2 groups were similar. History of coronary artery disease is more frequent in Syrian. SYNTAX I and SYNTAX II PCI were higher in Syrian patients whereas SYNTAX II CABG was similar compared with Turkish.

Operative and postoperative characteristics. The rate of off-pump surgery and number of grafts implanted were similar between groups (Table 2). Cardiopulmonary bypass time, aortic clamp time did not differ between groups. Intraaortic balloon pump use was similar between groups. Extubation time was longer in Syrian patients [9 (6-10) versus 7 (5-9.5), $p<0.001]$ (Table 3). Amount of hemorrhage was greater in Syrian; however, need for bleeding revision were similar between groups. Although sternal wound infection was more frequent in Syrian patients, sternal dehiscence and mediastinitis did not differ. Intensive care unit and clinic stay were not different between groups. In hospital atrial fibrillation, acute renal failure and postoperative stroke were similar between groups. In-hospital mortality was similar between groups. One year all-cause mortality did not differ between Syrian and Turkish patients $(n=3(4.5 \%)$ versus $\mathrm{n}=25$ (5.9\%), $p=0.63$ ) (Figure 1).
Table 1 - Baseline characteristics of Syrian and Turkish patients.

\begin{tabular}{|c|c|c|c|}
\hline Baseline characteristics & $\begin{array}{l}\text { Syrian } \\
(\mathrm{n}=67)\end{array}$ & $\begin{array}{l}\text { Turkish } \\
(\mathrm{n}=426)\end{array}$ & $P$-value \\
\hline Gender (Male/Female) & $54 / 13$ & $342 / 84$ & 0.952 \\
\hline Age (years) & $52.6 \pm 8.6$ & $59.9 \pm 7.5$ & $<0.001$ \\
\hline Body mass index $\left(\mathrm{kg} / \mathrm{m}^{2}\right)$ & $29.9 \pm 3.6$ & $27.1 \pm 3.8$ & $<0.001$ \\
\hline \multicolumn{4}{|l|}{ Risk factors } \\
\hline Smoking & $15(22.4)$ & $178(41.8)$ & 0.002 \\
\hline $\mathrm{DM}$ & $22(32.8)$ & $148(34.7)$ & 0.761 \\
\hline HT & $24(35.8)$ & $183(43.0)$ & 0.27 \\
\hline COPD & $9(13.4)$ & $69(16.2)$ & 0.565 \\
\hline PAD & $13(19.4)$ & $46(10.8)$ & 0.044 \\
\hline $\mathrm{CAD}$ & $23(34.3)$ & $51(11.9)$ & $<0.001$ \\
\hline Stroke & $2(3.0)$ & $22 \quad(5.2)$ & 0.35 \\
\hline \multicolumn{4}{|l|}{ Laboratory (mg/dl) } \\
\hline Total cholesterol & $279.4 \pm 89.6$ & $267.7 \pm 91.7$ & 0.331 \\
\hline LDL & $142.7 \pm 36.2$ & $134.2 \pm 37.3$ & 0.081 \\
\hline HDL & $46.1 \pm 6.2$ & $45.7 \pm 5.7$ & 0.594 \\
\hline CRP & $10.0 \pm 3.2$ & $6.7 \pm 3.4$ & $<0.001$ \\
\hline Carotid artery stenosis & $17(25.4)$ & $51(12.0)$ & 0.003 \\
\hline $\begin{array}{l}\text { Carotid artery stenosis } \\
\text { severity }(\%)\end{array}$ & $52.9 \pm 16.2$ & $66.0 \pm 22.5$ & 0.068 \\
\hline Ejection Fraction (\%) & $49.4 \pm 9.2$ & $50.6 \pm 9.1$ & 0.308 \\
\hline CEA & $2(3.0)$ & $22(5.2)$ & 0.442 \\
\hline Preop MI & $18(26.9)$ & $66(15.5)$ & $<0.001$ \\
\hline SYNTAX I & $35.8 \pm 8.9$ & $18.2 \pm 6.5$ & $<0.001$ \\
\hline SYNTAX II PCI & $44.2 \pm 9.0$ & $34.0 \pm 6.7$ & $<0.001$ \\
\hline SYNTAX II CABG & $27.2 \pm 10.6$ & $26.4 \pm 7.7$ & 0.417 \\
\hline \multicolumn{4}{|c|}{$\begin{array}{l}\text { DM - diabetes mellitus, HT - hypertension, COPD - chronic obstructive } \\
\text { pulmonary disease, PAD - peripheral artery disease; CAD - coronary } \\
\text { artery disease, CEA - carotid endarterectomy, preop MI - preoperative } \\
\text { myocardial infarction }\end{array}$} \\
\hline
\end{tabular}

Table 2 - Operative characteristics of Syrian and Turkish patients.

\begin{tabular}{lccc}
\hline Characteristics & $\begin{array}{l}\text { Syrian } \\
(\mathbf{n}=\mathbf{6 7})\end{array}$ & $\begin{array}{c}\text { Turkish } \\
(\mathbf{n}=\mathbf{4 2 6})\end{array}$ & $P$-value \\
\hline Off pump surgery (\%) & $4(6.0)$ & $24(5.6)$ & 0.912 \\
CPB time (min) & $83.0 \pm 37.5$ & $77.6 \pm 26.7$ & 0.164 \\
Clamp time (min) & $44.9 \pm 22.4$ & $42.8 \pm 15.7$ & 0.353 \\
By-pass graft number & $2.7 \pm 1.0$ & $2.8 \pm 1.0$ & 0.426 \\
\hline \multicolumn{4}{c}{ CPB - cardiopulmonary bypass } \\
\hline
\end{tabular}

Discussion. Our study showed that Syrian patients undergoing CABG surgery are approximately a decade younger. Obesity seems to be an important comorbidity in Syrian patients. Although coronary artery risk factors are similar with Turkish patients, history of coronary artery disease is more frequent in Syrian patients. Additionally, Syrian patients more frequently presented with the acute coronary syndrome. Syrian patients have more complex coronary artery disease. Higher SYNTAX II PCI score in Syrian patients is more related to coronary complexity rather than clinical risk factors. 
Compatible with SYNTAX II CABG score, in-hospital and one year mortality of Syrian patients is similar with Turkish patients. SYNTAX II CABG score predicts outcomes properly in Syrian patients. Longer extubation period may be related with ethnical differences in the metabolization of anesthetics.

Smoking prevalence was about $22 \%$ in our study. Depending on the survey of Turkish ministry of health which included 5760 refugees, prevalence of smoking is about 34\% among SR. ${ }^{6}$ Some patients may hide

Table 3 - Postoperative characteristics of Syrian and Turkish patients.

\begin{tabular}{|c|c|c|c|}
\hline Variables & $\begin{array}{l}\text { Syrian } \\
(\mathrm{n}=67)\end{array}$ & $\begin{array}{l}\text { Turkish } \\
(\mathrm{n}=426)\end{array}$ & $P$-value \\
\hline IABP $(\%)$ & $5(7.5)$ & $12(2.8)$ & 0.053 \\
\hline Extubation time (hours) & $9(6-10)^{*}$ & $7(5-9.5)$ & $<0.001$ \\
\hline Bleeding revision (\%) & $3(4.5)$ & $22(5.2)$ & 0.812 \\
\hline Hemorrhage $(\mathrm{ml})($ mean \pm SD $)$ & $582.1 \pm 183.3$ & $487.9 \pm 234.9$ & 0.002 \\
\hline Sternal dehiscence & $6(9.0)$ & $19(4.5)$ & 0.120 \\
\hline Wound infection & $8(11.9)$ & $19(4.5)$ & 0.012 \\
\hline Mediastinitis & 0 & $12 \quad(2.8)$ & 0.165 \\
\hline ARF & $3(4.5)$ & $12(2.8)$ & 0.463 \\
\hline Stroke & 0 & $4(0.9)$ & 0.427 \\
\hline MI & $3(4.5)$ & $5(1.2)$ & 0.78 \\
\hline Atrial fibrillation & $10(16.4)$ & $42(10.4)$ & 0.161 \\
\hline ICU stay (day) & $2.7 \pm 3.8$ & $2.3 \pm 1.6$ & 0.137 \\
\hline Clinic stay (day) & $4(4-5)^{*}$ & $5(5-6)$ & 0.101 \\
\hline In-hospital mortality & $1(1.5)$ & $13(3.1)$ & 0.476 \\
\hline One-year mortality & $3(4.5)$ & $25(5.9)$ & 0.63 \\
\hline $\begin{array}{r}{ }^{* *} \text { median and interquartil } \\
\text { pump, ARF - acute ren } \\
\text { ICU }\end{array}$ & $\begin{array}{l}\text { nge (IQR), IA } \\
\text { zilure, MI - my } \\
\text { tensive care un }\end{array}$ & $\begin{array}{l}\text { P - intraaorti } \\
\text { ocardial infarc } \\
t\end{array}$ & $\begin{array}{l}\text { dloon } \\
\text { n, }\end{array}$ \\
\hline
\end{tabular}

smoking and other habits since they think it may have negative impact on their treatment.

Average BMI was reported as 27.3 and obesity was predicted as $27.7 \%$ in the aforementioned survey. ${ }^{12}$ Our results are far greater than the survey predicted, which points out the importance of obesity as a significant risk factor for coronary artery disease in refugees. According to the survey, low level of physical activity prevalence is $67 \%$ in SR, which increased to $72 \%$ between ages of 45 and 59. Cultural food tradition, unsuitable lifestyle and low socioeconomic status are some reasons of obesity.

Posttraumatic stress disorder (PTSD) is more prevalent in SR with a rate of $83.4 \% .{ }^{13}$ Relationship between PTSD and coronary artery disease is well established. ${ }^{14}$ Although controversy exists, elevated CRP levels may be associated with psychological stress. ${ }^{15}$ On the other hand, higher incidence of acute coronary syndromes in SR may be related with higher CRP levels.

Higher prevalence of wound infection may be related to poor hygiene conditions. Besides, compatible with previous studies frequent lower extremity peripheral artery disease might be related to wound infections in Syrian patients. ${ }^{16}$ Approximately greater than $100 \mathrm{ml}$ of hemorrhage occurred in Syrian patients. Syrian patients have increased the frequency of acute coronary syndrome, thus excess hemorrhage may be related with dual antiplatelet use. Nevertheless, excess hemorrhage did not result in an excessive surgical revision.

History of cardiovascular disease was reported as $6.4 \%$ in the survey of the Ministry of Health. ${ }^{6}$ However,

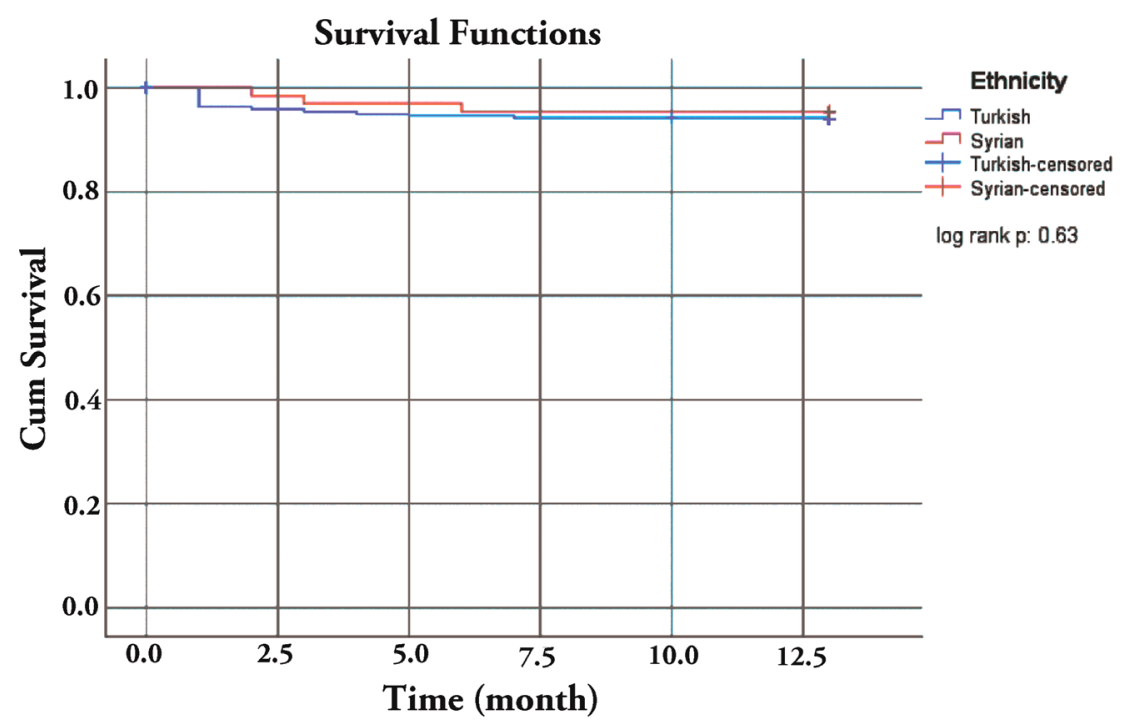

Figure 1 - Kaplan-Meier cumulative survival curves for 1-year mortality according to ethnicity 
history of coronary artery disease in our study is $34.3 \%$. Moreover, Syrian patients were more frequently admitted to hospital with the diagnosis of acute coronary syndrome. Compatible with these findings, increased SYNTAX I score in Syrian patients exposed more severe coronary artery disease. Our hospital is a tertiary center; therefore, this may cause an increased cumulative incidence of patients with history of CAD.

High SYNTAX II PCI score seems to be related with SYNTAX I score. SYNTAX II CABG score takes COPD and age more into account which poses a greater risk for CABG, but not for PCI. Similar frequencies of COPD in Syrian and Turkish patients in addition to younger Syrian patients result in similar scores of SYNTAX II CABG. Another reason for severe CAD in Syrian patients may be selection bias of patients between surgery and percutaneous treatment. Although we have not investigated thoroughly, refugees may prefer surgery over PCI, since surgery imposes a significant social, mental and economic burden. Thus, patients with more complex anatomies might have been referred for surgery. Nevertheless, SYNTAX II CABG score is compatible with our in-hospital and one year outcomes.

Restam et $\mathrm{al}^{17}$ reported increased mortality in coronary heart disease about $60 \%$ in Syria between 1996 and 2006. More than two-third of the increase was associated with increased risk factors such as hypertension and cholesterol. Authors emphasized the unhealthy life style due to urbanization and modernization of Arab societies. A cross- sectional survey reported annual cardiovascular crude death as 314 per 100,000 and cardiovascular deaths were responsible for $45 \%$ of overall mortality in $2007 .{ }^{8}$ Even before several years of conflict, cardiovascular mortality was worse in Syria compared with Turkey. ${ }^{18}$ A systematic literature review concluded that humanitarian emergencies are associated with increased cardiac morbidity and mortality persist for years. ${ }^{19}$ According to The Institute for Health Metrics and Evaluation (IHME) at the University of Washington, ischemic heart disease is the second cause of death after conflict and terror in Syria in $2016 .{ }^{20}$ Furthermore death due to ischemic heart disease increased 14.6\% between 2005-2016.

Several studies showed the increased incidence of coronary heart disease in immigrants compared with natural born citizens. ${ }^{21-23}$ Beyond genetic factors, socioeconomic status play role in worse cardiovascular outcomes. However, Hedlund et $\mathrm{al}^{24}$ showed increased acute myocardial infarction incidence in the early years after immigration independent of socioeconomic status. This early increase may be related to increased psychological stress. Although not assessed in our study, we observe significantly increased psychological stress in Syrian patients whose contribution to disease progression may not be underestimated. In addition to thorough clinical and surgical data, we presented risk scores taking angiographic features into account. Not only nationwide but also international multicenter collaborative studies are required in order to set policies and improve the cardiovascular status of SR.

Study limitations. Retrospective nature of the study is the major limitation. Some deaths were only confirmed from death reporting system which does not present cause of death in details. Although cardiovascular causes comprise greater than $90 \%$ of mortality, we found appropriate to present one year all-cause mortality in this study.

In conclusion, Syrian patients had more complex coronary artery disease and higher SYNTAX I and SYNTAX II PCI scores, but not SYNTAX II CABG score compared with Turkish patients. Intraoperative and postoperative complications were similar. In-hospital mortality and one year all-cause mortality of Syrian patients were similar with Turkish patients. Surgical outcomes of Syrian patients were acceptable. Primary prevention, particularly for obesity, must be provided. Aggressive secondary preventive measures must be taken due to increased severity of coronary artery disease.

\section{References}

1. Syria Emergency [Internet]. [Accessed 2018 March 4]. Available from: http://www.unhcr.org/syria-emergency. html?query=syrian.

2. Distribution of Syrian Refugees in the Scope of Temporary Protection by Year [Internet]. [Accessed 2018 July 10]. Available from: http://www.goc.gov.tr/icerik3/gecicikoruma_363_378_4713

3. Sahlool Z, Sankri-Tarbichi AG, Kherallah M. Evaluation report of health care services at the Syrian refugee camps in Turkey. Avicenna J Med 2012; 2: 25-28.

4. Doocy S, Lyles E, Roberton T, Akhu-Zaheya L, Oweis A, Burnham G. Prevalence and care-seeking for chronic diseases among Syrian Refugees in Jordan. BMC Public Health 2015; 15: 1097.

5. Strong J, Varady C, Chahda N, Doocy S, Burnham G. Health status and health needs of older refugees from Syria in Lebanon. Confl Health 2015; 9: 12.

6. Şimşek Z, Yentur Doni N, Gül Hilali N, Yildirimkaya G. A community-based survey on Syrian refugee women's health and its predictors in Şanliurfa, Turkey. Women Health 2017; 1-15.

7. Pfortmueller CA, Schwetlick M, Mueller T, Lehmann B, Exadaktylos AK. Adult asylum seekers from the Middle East including Syria in central Europe: What are their health care problems? PLoS One 2016; 11: e0148196. 
8. Maziak W, Rastam S, Mzayek F, Ward KD, Eissenberg T, Keil U. Cardiovascular health among adults in Syria: a model from developing countries. Ann Epidemiol 2007; 17: 713-720.

9. Collins DRJ, Jobanputra K, Frost T, Muhammed S, Ward A, Shafei AA, et al. Cardiovascular disease risk and prevention amongst Syrian Refugees: mixed methods study of Médecins Sans Frontières programme in Jordan. Confl Health 2017; 11: 14.

10. Al-Ammouri I, Ayoub F. Heart Disease in Syrian Refugee Children: Experience at Jordan University Hospital. Ann Glob Health 2016; 82: 300-306.

11. Demir D, Abanoz M, Tulay CM, Aydın MS, Kasapoğlu BÖ, Merdanoğlu $\mathrm{M}$, et al. Outcomes of coronary artery bypass surgery in Syrian refugees. Int J Clin Exp Med 2016; 9: 13195-13199

12. Health Status Survey of Syrian Refugees in Turkey. Accessed 2018 March 4]. Available from: https://sbu.saglik.gov.tr/ Ekutuphane/Yayin/542.

13. Acarturk C, Cetinkaya M, Senay I, Gulen B, Aker T, Hinton D. Prevalence and predictors of posttraumatic stress and depression symptoms among syrian refugees in a refugee camp. J Nerv Ment Dis 2018; 206: 40-45.

14. Ahmadi N, Hajsadeghi F, Mirshkarlo HB, Budoff M, Yehuda R, Ebrahimi R. Post-traumatic stress disorder, coronary atherosclerosis, and mortality. Am J Cardiol 2011; 108: 29-339.

15. Eraly SA, Nievergelt CM, Maihofer AX, Barkauskas DA, Biswas N, Agorastos A, et al. Marine Resiliency Study Team. Assessment of plasma C-reactive protein as a biomarker of posttraumatic stress disorder risk. JAMA Psychiatry 2014; 71: 423-431.

16. Fakih MG, Sharma M, Khatib R, Berriel-Cass D, Meisner S, Harrington S, Saravolatz L. Increase in the rate of sternal surgical site infection after coronary artery bypass graft: a marker of higher severity of illness. Infect Control Hosp Epidemiol 2007; 28: 655-660.
17. Rastam S, Al Ali R, Maziak W, Mzayek F, Fouad FM, O'Flaherty M, et al. Explaining the increase in coronary heart disease mortality in Syria between 1996 and 2006. BMC Public Health 2012; 12: 754.

18. Global Atlas on cardiovascular disease prevention and control. [Accessed 2018 March 4]. Available from: http://www.paho. org/hq/index.php?option=com_docman $\&$ task=doc_view\&gid $=21049$ \&Itemid $=270 \&$ lang $=$ en.

19. Hayman KG, Sharma D, Wardlow RD, Singh S. Burden of cardiovascular morbidity and mortality following humanitarian emergencies: a systematic literature review. Prehosp Disaster Med 2015; 30: 80-88.

20. What causes the most deaths? [Internet]. [Accessed 2018 March 4]. Available from: http://www.healthdata.org/syria.

21. Byberg S, Agyemang C, Zwisler AD, Krasnik A, Norredam M. Cardiovascular disease incidence and survival: Are migrants always worse off? Eur J Epidemiol 2016; 31: 667-677.

22. Bo A, Zinckernagel L, Krasnik A, Petersen JH, Norredam M. Coronary heart disease incidence among non-Western immigrants compared to Danish-born people: effect of country of birth, migrant status, and income. Eur J Prev Cardiol 2015; 22: 1281-1289.

23. Rabanal KS, Selmer RM, Igland J, Tell GS, Meyer HE. Ethnic inequalities in acute myocardial infarction and stroke rates in Norway 1994-2009: a nationwide cohort study (CVDNOR). BMC Public Health 2015; 15: 1073.

24. Hedlund E, Lange A, Hammar N. Acute myocardial infarction incidence in immigrants to Sweden. Country of birth, time since immigration, and time trends over 20 years. Eur J Epidemiol 2007; 22: 493-503. 